\title{
Association between ADCY9 Gene Polymorphisms and Ritodrine Treatment Outcomes in Patients with Preterm Labor
}

\author{
Nari Lee ${ }^{1,+}$, Ha-Young Yoon ${ }^{1,+}$, Jin-Young Park ${ }^{1}$, Young-Ju Kim ${ }^{2} \mathbb{D}$, Han-Sung Hwang ${ }^{3} \mathbb{D}$, Jeong Yee ${ }^{1, *}$ \\ and Hye-Sun Gwak 1,*iD
}

Citation: Lee, N.; Yoon, H.-Y.; Park, J.-Y.; Kim, Y.-J.; Hwang, H.-S.; Yee, J.; Gwak, H.-S. Association between ADCY9 Gene Polymorphisms and Ritodrine Treatment Outcomes in Patients with Preterm Labor. Pharmaceutics 2021, 13, 1653. https: / / doi.org/10.3390/ pharmaceutics13101653

Academic Editors: Francisco Abad Santos, Pablo Zubiaur and Pedro Dorado

Received: 27 August 2021 Accepted: 8 October 2021

Published: 10 October 2021

Publisher's Note: MDPI stays neutral with regard to jurisdictional claims in published maps and institutional affiliations.

Copyright: (c) 2021 by the authors. Licensee MDPI, Basel, Switzerland. This article is an open access article distributed under the terms and conditions of the Creative Commons Attribution (CC BY) license (https:/ / creativecommons.org/licenses/by/ $4.0 /)$.
1 College of Pharmacy and Graduate School of Pharmaceutical Sciences, Ewha Womans University, Seoul 03760, Korea; leenarisme@gmail.com (N.L.); hayoungdymphnayoon@gmail.com (H.-Y.Y.); kellyjeans87@naver.com (J.-Y.P.)

2 Department of Obstetrics and Gynecology, Ewha Womans University School of Medicine, Seoul 07985, Korea; kkyj@ewha.ac.kr

3 Department of Obstetrics and Gynecology, Konkuk University Medical Center, Konkuk University School of Medicine, Seoul 05030, Korea; hwanghs@kuh.ac.kr

* Correspondence: jjjhello1@naver.com (J.Y.); hsgwak@ewha.ac.kr (H.-S.G.); Tel.: +82-2-3277-3052 (J.Y.); +82-2-3277-4376 (H.-S.G.); Fax: +82-2-3277-3051 (J.Y.); +82-2-3277-3051 (H.-S.G.)

+ These authors contribute equally to this work.

\begin{abstract}
The purpose of this study was to investigate the genetic effects of $A D C Y 9$ on ritodrine responses in patients with preterm labor. Five single nucleotide polymorphisms (SNPs) of the ADYC9 gene in 163 patients in preterm labor were genotyped: rs879619, rs2601796, rs2531988, rs2531995, and rs2230739. Additionally, rs598961 of the PDE4B gene and rs1042719 of the ADRB2 gene were included for analysis. Patients with CC genotype of ADCY9 rs879619 had a 2.0-fold (95\% confidence interval [CI]: 1.3, 3.2) higher hazard of time to delivery than T allele carriers. Patients with combined genotypes of CC in ADCY9 rs879619, AA in PDE4B rs598961, and GC, CC in ADRB2 rs1042719 showed a greater hazard of time to delivery than patients with other combinations (adjusted hazard ratio [AHR] 3.2; 95\% CI: 1.7, 6.3), whereas patients carrying the C allele of ADCY9 rs2531995, G allele of PDE4B rs598961, and GG genotype of ADRB2 rs1042719 had a lower hazard of time to delivery than patients carrying other genotypes (AHR 0.4; 95\% CI: 0.2, 0.7). Regarding ritodrine-induced adverse drug events (ADEs), height less than $160 \mathrm{~cm}$ and CC genotype of ADCY9 rs2531995 showed a greater risk of ADEs. The results of our study suggest that $A D C Y 9$ polymorphisms could affect the efficacy and safety of $\beta_{2}$-adrenergic agonists.
\end{abstract}

Keywords: adenylyl cyclase 9 gene; adverse drug events; preterm labor; ritodrine; single nucleotide polymorphism; time to delivery

\section{Introduction}

Preterm birth is a delivery occurring before 37 weeks of gestation and its global incidence is estimated at 15 million annually [1]. As preterm birth is the leading cause of neonatal morbidity and mortality, appropriate tocolytic agents (including $\beta_{2}$-adrenergic agonists) are recommended for the treatment of preterm labor.

Ritodrine binds to $\beta_{2}$-adrenergic receptors (ADRB2) on uterine smooth muscle, resulting in increased levels of intracellular cyclic adenosine- $3^{\prime}, 5^{\prime}$-monophosphate (cAMP), which leads to relaxation of the uterine smooth muscle [2-4]. In previous studies, genetic polymorphisms of $A D R B 2$ and phosphodiesterase $4 \mathrm{~B}(P D E 4 B)$ were considered important factors for ritodrine treatment response by regulating the intracellular concentration of cAMP $[5,6]$.

Adenylate cyclase (ADCY), which is stimulated by G protein-coupled receptors (such as ADRB2), catalyzes the conversion of ATP to cAMP and controls smooth muscle contractility. Among the ADCY family, ADCY9 is classified into a separate category which is 
only activated by the Gs alpha subunit [7]. The ADCY9 gene is encoded on chromosome 16 . Several studies have shown that $A D C Y 9$ polymorphisms are associated with responses of airway smooth muscle to $\beta_{2}$-adrenergic agents [8-10]. Although ADCY9 polymorphisms could also have effects on the uterine smooth muscle [7], no studies have been conducted in the treatment of preterm labor. Therefore, this study aimed to investigate the potential role of ADCY9 gene polymorphisms that could alter ritodrine efficacy and ritodrine-induced adverse drug events (ADEs) in pregnant women with preterm labor.

\section{Methods}

\subsection{Patients}

This was a prospective study conducted between January 2010 and December 2014 at Ewha Womans University Mokdong Hospital. We enrolled patients aged $\geq 18$ years who received ritodrine treatment for preterm labor (i.e., uterine contractions of more than 3 in $10 \mathrm{~min}$ and cervical change) with an intact membrane at gestational age 20 to 36 weeks and provided written informed consent. Patients were excluded if (1) they received ritodrine treatment for McDonald procedure; (2) they had pre-eclampsia, fetal distress, severe oligohydramnios, placenta abruption, placenta previa, or spontaneous premature membrane rupture; (3) their continuation of pregnancy would be detrimental; (4) they had cardiovascular disease, hyperthyroidism, or asthma, which could preclude the detection of outcomes; or (5) there were no blood samples. This study was performed in accordance with ethical standards of the Declaration of Helsinki and approved by the Institutional Review Board (IRB) of Ewha Womans University Mokdong Hospital (No. 217-1-26, 6 January 2010). Informed consent was obtained from all patients before enrollment.

\subsection{Drug Administration}

Ritodrine (Lavopa ${ }^{\circledR}$; JW Pharmaceutical, Seoul, Korea) by intravenous infusion started at the rate of $0.05 \mathrm{mg} / \mathrm{min}$ and increased by $0.05 \mathrm{mg} / \mathrm{min}$ every $10 \mathrm{~min}$ until uterine quiescence was achieved. After that, maintenance therapy was given for $12-48 \mathrm{~h}$ at a dose of $0.05 \mathrm{mg} / \mathrm{min}$.

\subsection{Outcomes and Data Collection}

We reviewed medical records and collected data, including maternal age, height, weight, body mass index, gestational age at drug administration, modified Bishop score, multiple pregnancy, and delivery information.

The primary outcome was time to delivery, which was defined as the time interval from initiation of ritodrine therapy to fetal delivery, and the secondary outcome was ritodrine-induced ADEs. ADEs were defined as tachycardia over 100 beats $/ \mathrm{min}$, palpitation, dyspnea, shortness of breath, or pulmonary edema requiring drug discontinuation or dose reduction.

\subsection{Selection of Single Nucleotide Polymorphisms (SNPs)}

SNPs of ADCY9 were selected based on other studies [8-10]. Genetic information (e.g., rsID, chromosomal position, reference/alternate allele, and function) was obtained from the University of California Santa Cruz genome browser [11] and Asian minor allele frequency (MAF) and linkage disequilibrium (LD) data of each SNP were collected from Haploreg v4.1 [12]. Using the tagger function of the Haploview v4.2 [13], ADCY9 SNPs were assorted. SNPs were considered redundant in case of strong $\operatorname{LD}\left(\mathrm{r}^{2} \geq 0.8\right)$. In addition, $P D E 4 B$ and $A D R B 2$ SNPs, which were reported in previous studies as affecting ritodrine efficacy and ADEs, were included for analysis $[5,6]$.

\subsection{Genotyping Methods}

Genomic DNA was extracted from EDTA-treated whole blood using QIAamp DNA Blood Mini Kits (QIAGEN, Hilden, Germany). PDE4B rs598961 (c.232-1587 G > A) and the following ADCY9 SNPs were genotyped by a single-base primer extension assay using 
SNaPShot Multiplex kit (Applied Biosystems, Foster City, CA, USA): rs879619 (c.*730 C > T), rs2601796 (c.1694-30417 C > T), rs2531988 (c.2679 + 700 T > G), rs2531995 (c. *2309 $\mathrm{C}>\mathrm{T}$ ), and rs2230739 (c.13 T > C). In addition, TaqMan genotyping assay was used for $A D R B 2$ rs1042719 (c.1053 G > C).

\subsection{Statistical Analyses}

Time to delivery data were summarized by the Kaplan-Meier method, and log-rank test was used to determine statistical differences between two groups. To compare patients with and without ADEs, chi-squared and Fisher's exact tests were carried out. Each SNP was tested in both dominant and recessive models, and the most appropriate model was selected by considering both effect size and statistical significance. As ADCY9, PDE4B, and ADRB2 shared the CAMP signaling pathway in uterine relaxation, we also investigated the combined genetic effects of $A D C Y 9 / P D E 4 B / A D R B 2$ on time to delivery by grouping genotypes with similar trends and comparing them.

A Cox proportional hazards regression model and logistic regression model were used to identify the independent factors for time to delivery and ritodrine-induced ADEs, respectively. Multivariable analysis with backward elimination was performed with variables of $p<0.05$ in univariate analysis in addition to known factors (age and ADRB2 rs1042719 [5]).

The Hosmer-Lemeshow goodness-of-fit test was used to evaluate the model fitting. An analysis of the area under the receiver operating curve (AUROC) was conducted to assess the ability of risk factors to predict ritodrine-induced ADEs. All statistical analysis was performed using SPSS 20.0 software (IBM Corp., Armonk, NY, USA). A $p<0.05$ was considered statistically significant.

\subsection{In Silico Analyses}

The Polymorphism in microRNAs and their TargetSites (PolymiRTs database; University of Tennessee Health Sciences Center, Memphis, TN, USA) was used to predict the functional impact of polymorphisms in the 3-prime untranslated region (3'-UTR) [14]. Using information about $3^{\prime}$-UTR sequence, this bioinformatics tool provides potential SNPs that could create, destroy, or modulate an miRNA-binding site. The context+ score, which incorporated site-type, 3' pairing, local AU, position, target site abundance, and seed-pairing stability, was used to evaluate the miRNA binding to the $3^{\prime}$-UTR sequence [15]. The score with a more negative value indicates the more likelihood of target site disruption or new site creation [14].

\section{Results}

A total of 236 patients were enrolled, and 163 were eligible for study. Seventy-three patients were excluded due to the following reasons: ritodrine treatment for McDonald procedure $(n=10)$, severe cases requiring labor before arriving at the hospital $(n=15)$, underlying cardiovascular diseases $(n=10)$, and lack of samples $(n=38)$.

Mean maternal age and height were $30.9 \pm 3.5$ years and $161.3 \pm 4.4 \mathrm{~cm}$, respectively. Mean weight and BMI were $62.4 \pm 4.4 \mathrm{~kg}$ and $24.0 \pm 4.7 \mathrm{~kg} / \mathrm{m}^{2}$, respectively. Gestational age at drug therapy $\geq 32$ weeks $(p<0.001)$ and modified Bishop score $\geq 3(p=0.001)$ were statistically significant factors for time to delivery (Table 1). Except for two cases of miscarriage, the percentage of spontaneous preterm birth was $47 \%$. Mean gestational age at delivery was $36.2 \pm 3.8$ weeks. 
Table 1. Effects of demographic characteristics on time to delivery.

\begin{tabular}{|c|c|c|c|}
\hline Characteristic & $\begin{array}{c}\text { Number of } \\
\text { Patients }\end{array}$ & $\begin{array}{l}\text { Time to Delivery } \\
\text { Median }(95 \% \text { CI) }\end{array}$ & $p$ Value \\
\hline \multicolumn{4}{|l|}{ Age (years) } \\
\hline$<30$ & 59 & $1168.6(764.3-1572.8)$ & 0.492 \\
\hline$\geq 30$ & 104 & $1040.0(670.5-1409.5)$ & \\
\hline \multicolumn{4}{|l|}{ Height $(\mathrm{cm})$} \\
\hline$<160$ & 53 & $1027.2(580.6-1473.7)$ & 0.419 \\
\hline$\geq 160$ & 110 & $1168.6(873.7-1463.4)$ & \\
\hline \multicolumn{4}{|l|}{ Weight (kg) } \\
\hline$<60$ & 66 & $978.6(476.1-1481.0)$ & 0.983 \\
\hline$\geq 60$ & 97 & $1230.6(964.5-1496.7)$ & \\
\hline \multicolumn{4}{|l|}{$\mathrm{BMI}\left(\mathrm{kg} / \mathrm{m}^{2}\right)$} \\
\hline$<25$ & 112 & $1247.8(940.7-1554.9)$ & 0.934 \\
\hline$\geq 25$ & 51 & $1040.0(656.0-1424.0)$ & \\
\hline \multicolumn{4}{|c|}{ Gestational age at drug therapy (weeks) } \\
\hline$<32$ & 111 & $1408.1(1172.8-1643.5)$ & $<0.001$ \\
\hline$\geq 32$ & 52 & $548.0(272.0-824.0)$ & \\
\hline \multicolumn{4}{|l|}{ Modified Bishop score ${ }^{a}$} \\
\hline$<3$ & 109 & $1247.8(1112.9-1382.8)$ & 0.001 \\
\hline$\geq 3$ & 19 & $156.9(25.5-288.3)$ & \\
\hline Multiple pregnancy $b$ & & & 0.207 \\
\hline Single & 125 & $1072.6(800.2-1345.1)$ & \\
\hline Multiple & 18 & $631.1(147.2-1114.9)$ & \\
\hline
\end{tabular}

The genotypes and MAF of studied SNPs of the ADCY9 gene are shown in Table 2. All genotype distributions were consistent with the Hardy-Weinberg equilibrium. In univariate analysis, rs879619 (C > T) and rs2531995 (C > T) of ADCY9 and rs1042719 $(\mathrm{G}>\mathrm{C}$ ) of $A D R B 2$ were significantly associated with time to delivery. $\mathrm{T}$ allele carriers of rs879619 had a longer time to delivery than patients with CC genotype $(p=0.018)$. For rs2531995, patients carrying TT genotype showed a shorter time to delivery than $C$ allele carriers $(p=0.039)$. C allele carriers of rs1042719 in the ADRB2 gene had a shorter time to delivery than those with GG genotype $(p=0.012)$. The effects of combined genotypes of the $A D C Y 9, P D E 4 B$ and $A D R B 2$ SNPs on time to delivery were also analyzed. Patients with the CC genotype of $A D C Y 9$ rs879619, the AA genotype of $P D E 4 B$ rs598961, and C allele of $A D R B 2$ rs1042719 had a shorter median time to delivery $(p=0.004)$, whereas patients carrying the C allele of $A D C Y 9$ rs2531995, G allele of PDE4B rs598961, and GG genotype of $A D R B 2$ had a longer median time to delivery $(p<0.001)$ compared to patients with other genotypes, respectively.

Table 3 shows results from multivariable regression analysis after adjusting for factors with $p<0.05$, besides age and ADRB2 rs1042719 (Model I). Patients carrying CC genotype of ADCY9 rs879619 had a greater hazard of time to delivery than patients with T allele (adjusted hazard ratio [AHR] 2.0; 95\% confidence interval [CI]: 1.3, 3.2). On the contrary, age and rs2531995 failed to remain in the final model. Model II included combined genotypes of ADCY9 rs879619, PDE4B rs598961, and ADRB2 rs1042719 instead of ADCY9 rs879619 of Model I. Patients with the combined genotypes of CC in ADCY9 rs879619, AA in PDE4B rs598961, and C allele in $A D R B 2$ rs1042719 showed a greater hazard of time to delivery than patients with other combinations (AHR 3.2; 95\% CI: 1.7, 6.3). Model III was constructed with the combined genotype of ADCY9 rs2531995, PDE4B rs598961, and ADRB2 rs1042719 instead of $A D C Y 9$ rs 2531995 of Model I. Patients carrying the C allele of ADCY9 rs879619, G allele of $P D E 4 B$ rs598961, and GG genotype of $A D R B 2$ rs1042719 had a lesser hazard of time to delivery than patients carrying other genotypes (AHR 0.4; 95\% CI: 0.2, 0.7). Gestational age at drug therapy ( $\geq 32$ weeks) and modified Bishop score $(\geq 3)$ were significant factors regardless of the constructed models. 
Table 2. Effects of grouped genotypes on time to delivery.

\begin{tabular}{|c|c|c|c|c|c|}
\hline Gene Polymorphism & $\begin{array}{l}\text { Minor Allele } \\
\text { Frequency (\%) }\end{array}$ & $\begin{array}{l}\text { Grouped } \\
\text { Genotype }\end{array}$ & $\begin{array}{c}\text { Number of } \\
\text { Patients }\end{array}$ & $\begin{array}{l}\text { Time to Delivery } \\
\text { Median (95\% CI) }\end{array}$ & $p$ Value \\
\hline \multicolumn{6}{|l|}{ ADCY9 } \\
\hline \multirow[t]{2}{*}{$\operatorname{rs} 879619(C>T)^{a}$} & 27.4 & CC & 82 & $811.6(532.9-1090.4)$ & 0.018 \\
\hline & & $\mathrm{CT}, \mathrm{TT}$ & 79 & 1300.8 (1187.1-1414.5) & \\
\hline \multirow[t]{2}{*}{$\operatorname{rs} 2601796(C>T)^{a}$} & 7.6 & $\mathrm{CC}, \mathrm{CT}$ & 24 & $978.6(495.4-1461.7)$ & 0.650 \\
\hline & & $\mathrm{TT}$ & 137 & $1168.6(874.4-1462.7)$ & \\
\hline \multirow[t]{2}{*}{ rs2531988 (T > G) } & 28.6 & $\mathrm{TT}, \mathrm{GT}$ & 83 & $1275.4(974.3-1576.4)$ & 0.565 \\
\hline & & GG & 80 & 934.7 (679.5-1190.0) & \\
\hline \multirow[t]{2}{*}{ rs2531995 (C > T) } & 35.0 & $\mathrm{CC}, \mathrm{CT}$ & 147 & $1190.7(961.0-1420.4)$ & 0.039 \\
\hline & & $\mathrm{TT}$ & 16 & $613.9(0-1237.0)$ & \\
\hline \multirow{2}{*}{ rs2230739 $(\mathrm{T}>\mathrm{C})^{\mathrm{b}}$} & 38.2 & $\mathrm{TT}, \mathrm{CT}$ & 142 & $1168.6(940.2-1396.9)$ & 0.340 \\
\hline & & $\mathrm{CC}$ & 20 & $613.9(42.4-1185.5)$ & \\
\hline \multirow{3}{*}{$\begin{array}{c}P D E 4 B \\
\text { rs598961 (G>A) }\end{array}$} & & & & & \\
\hline & 37.1 & GG, GA & 89 & $1298.9(1162.2-1435.7)$ & 0.102 \\
\hline & & AA & 58 & $828.6(553.3-1103.9)$ & \\
\hline \multirow{3}{*}{$\begin{array}{c}A D R B 2 \\
\text { rs1042719 }(\mathrm{G}>\mathrm{C})^{\mathrm{b}}\end{array}$} & & & & & \\
\hline & 44.5 & GG & 53 & 1338.5 (950.1-1727.0) & 0.012 \\
\hline & & $\mathrm{GC}, \mathrm{CC}$ & 109 & $978.6(680.5-1276.6)$ & \\
\hline \multicolumn{6}{|l|}{ ADCY9/PDE4B/ADRB2 } \\
\hline \multirow[t]{2}{*}{ rs879619/rs598961/rs1042719 d } & $\mathrm{N} / \mathrm{A}$ & $\mathrm{CC} / \mathrm{AA} / \mathrm{GC}, \mathrm{CC}$ & 20 & $568.6(0-1261.9)$ & 0.004 \\
\hline & & Others & 125 & $1274.8(1077.3-1432.2)$ & \\
\hline \multirow[t]{2}{*}{ rs2531995/rs598961/rs1042719 c } & $\mathrm{N} / \mathrm{A}$ & $\mathrm{CC}, \mathrm{CT} / \mathrm{GG}, \mathrm{GA} / \mathrm{GG}$ & 25 & $1875.5(1084.2-2666.8)$ & $<0.001$ \\
\hline & & Others & 122 & $978.6(738.4-1218.7)$ & \\
\hline
\end{tabular}

N/A: not available. ${ }^{a} 2$ missing data for rs879619 and rs2601796, b 1 missing data for rs2230739 and rs1042719, b 2 missing data for rs2601796, c 16 missing data for rs598961 and rs2531995/rs598961/ rs1042719, d 18 missing data for rs879619/rs598961/rs1042719.

Table 3. Multivariable analysis of time to delivery.

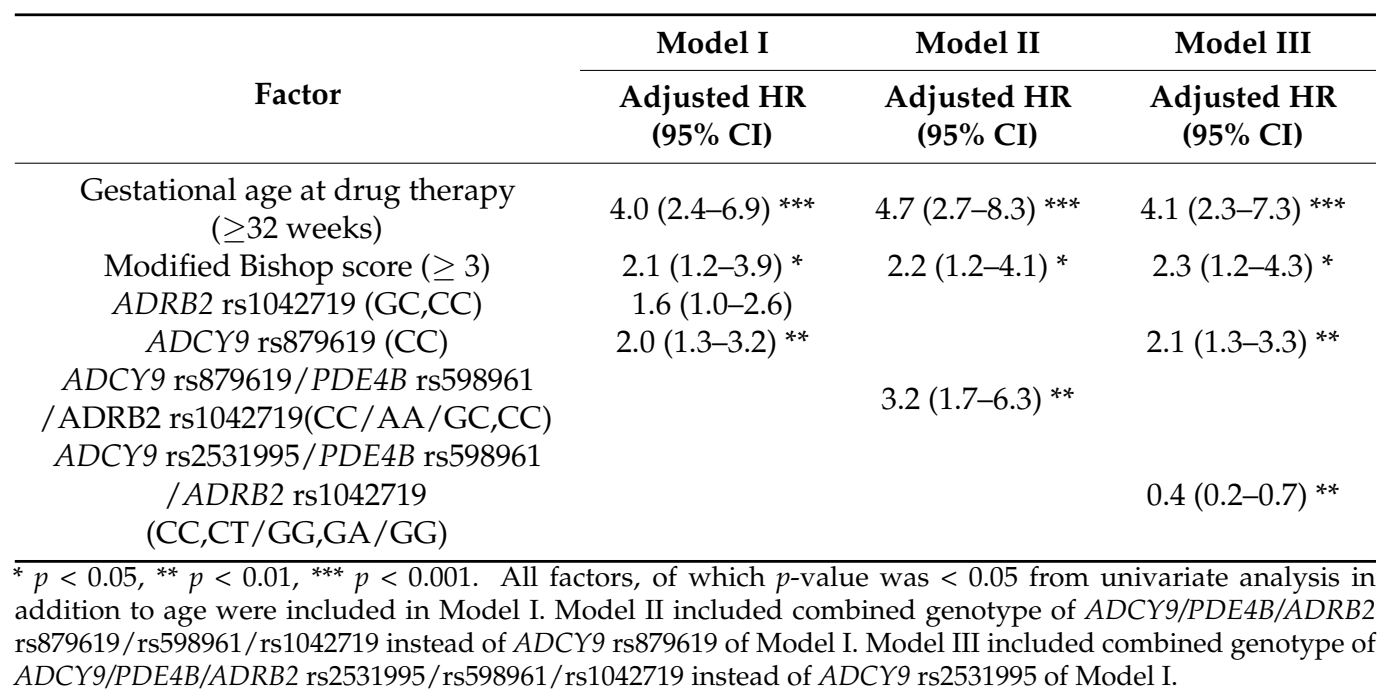

For ritodrine-induced ADEs, height $(p=0.009)$ and rs2531995 $(C>T)$ of the ADCY9 gene $(p=0.013)$ showed a significant association with ADEs (Table 4). After adjusting for factors with $p<0.05$, besides age and rs1042719 of the ADRB2 gene, height $<160 \mathrm{~cm}$, and CC genotype of ADCY9 rs2531995 showed a greater risk of ADEs (adjusted odds ratio [AOR] 2.5, 95\% CI: 1.2, 5.2; and AOR 2.2, 95\% CI: 1.1, 4.2, respectively) (Table 5). The Hosmer-Lemeshow test for ADEs, which included height and rs2531995, showed a good fit $\left(\chi^{2}=0.174, p=0.917\right)$. The AUROC was 0.660 (95\% CI: 0.567, 0.753). 
Table 4. Effects of demographic characteristics and grouped genotypes in ADCY9 on adverse drug events.

\begin{tabular}{|c|c|c|c|c|}
\hline \multirow{2}{*}{ Characteristic } & \multirow{2}{*}{$\begin{array}{l}\text { Number of } \\
\text { Patients (\%) }\end{array}$} & \multicolumn{2}{|c|}{ Adverse Drug Events } & \multirow{2}{*}{$p$ Value } \\
\hline & & Yes $(n=46)$ & No $(n=117)$ & \\
\hline \multicolumn{5}{|l|}{ Age (years) } \\
\hline$<30$ & $59(36.2)$ & $15(32.6)$ & $44(37.6)$ & 0.550 \\
\hline$\geq 30$ & $104(63.8)$ & $31(67.4)$ & $73(62.4)$ & \\
\hline Mean \pm S.D & $31.0 \pm 3.7$ & $31.0 \pm 4.4$ & $30.9 \pm 3.5$ & 0.880 \\
\hline \multicolumn{5}{|l|}{ Height (cm) } \\
\hline$<160$ & $53(32.5)$ & $22(47.8)$ & $31(26.5)$ & 0.009 \\
\hline$\geq 160$ & $110(67.5)$ & $24(52.2)$ & $86(73.5)$ & \\
\hline Mean \pm S.D & $161.2 \pm 4.5$ & $160.3 \pm 4.7$ & $161.6 \pm 4.4$ & 0.083 \\
\hline \multicolumn{5}{|l|}{ Weight (kg) } \\
\hline$<60$ & $66(40.5)$ & $24(52.2)$ & $42(35.9)$ & 0.057 \\
\hline$\geq 60$ & $97(59.5)$ & $22(47.8)$ & $75(64.1)$ & \\
\hline Mean \pm S.D & $62.5 \pm 8.5$ & $61.0 \pm 8.2$ & $63.0 \pm 8.6$ & 0.176 \\
\hline \multicolumn{5}{|l|}{$\mathrm{BMI}\left(\mathrm{kg} / \mathrm{m}^{2}\right)$} \\
\hline$<25$ & 112 (68.7) & 33 (71.7) & $79(67.5)$ & 0.601 \\
\hline$\geq 25$ & $51(31.3)$ & $13(28.3)$ & $38(32.5)$ & \\
\hline Mean \pm S.D & $24.0 \pm 3.0$ & $23.7 \pm 2.8$ & $24.1 \pm 3.2$ & 0.458 \\
\hline \multicolumn{5}{|c|}{$\begin{array}{c}\text { Gestational age } \\
\text { at drug therapy(weeks) }\end{array}$} \\
\hline$<32$ & $111(68.1)$ & $33(71.7)$ & $78(66.7)$ & 0.532 \\
\hline$\geq 32$ & $52(31.9)$ & $13(28.3)$ & $39(33.3)$ & \\
\hline Mean \pm S.D & $29.7 \pm 3.7$ & $29.0 \pm 3.9$ & $29.9 \pm 3.6$ & 0.151 \\
\hline \multicolumn{5}{|l|}{ Modified Bishop score $^{\text {a }}$} \\
\hline$<3$ & $109(85.2)$ & $32(91.4)$ & $77(82.8)$ & 0.221 \\
\hline$\geq 3$ & $19(14.8)$ & $3(8.6)$ & $16(17.2)$ & \\
\hline Multiple pregnancy & & & & 0.098 \\
\hline Single & $125(87.4)$ & $35(79.5)$ & $90(90.9)$ & \\
\hline Multiple & $18(12.6)$ & $9(20.5)$ & $9(9.1)$ & \\
\hline \multicolumn{5}{|l|}{$\operatorname{rs} 879619(\mathrm{C}>\mathrm{T})^{\mathrm{c}}$} \\
\hline $\mathrm{CC}$ & $82(50.9)$ & $22(47.8)$ & $60(52.2)$ & 0.618 \\
\hline $\mathrm{CT}, \mathrm{TT}$ & $79(49.1)$ & $24(52.2)$ & $55(47.8)$ & \\
\hline \multicolumn{5}{|l|}{$\operatorname{rs} 2601796(\mathrm{C}>\mathrm{T})^{\mathrm{c}}$} \\
\hline $\mathrm{CC}, \mathrm{CT}$ & $24(14.9)$ & $7(15.6)$ & $17(14.7)$ & 0.886 \\
\hline $\mathrm{TT}$ & $137(85.1)$ & $38(84.4)$ & $99(85.3)$ & \\
\hline \multicolumn{5}{|l|}{ rs2531988 (T > G) } \\
\hline $\mathrm{TT}, \mathrm{GT}$ & $83(50.9)$ & $22(47.8)$ & $61(52.1)$ & 0.620 \\
\hline GG & $80(49.1)$ & $24(52.2)$ & $56(47.9)$ & \\
\hline \multicolumn{5}{|l|}{ rs2531995 (C > T) } \\
\hline $\mathrm{CC}$ & $64(39.3)$ & $25(54.3)$ & $39(33.3)$ & 0.013 \\
\hline $\mathrm{CT}, \mathrm{TT}$ & $99(60.7)$ & $21(45.7)$ & $78(66.7)$ & \\
\hline \multicolumn{5}{|l|}{ rs2230739 $(\mathrm{T}>\mathrm{C})^{\mathrm{d}}$} \\
\hline $\mathrm{TT}$ & $66(40.7)$ & $21(45.7)$ & $45(38.8)$ & 0.423 \\
\hline $\mathrm{CT}, \mathrm{CC}$ & $96(59.3)$ & $25(54.3)$ & $71(61.2)$ & \\
\hline \multicolumn{5}{|c|}{$P D E 4 B$ rs598961 (G>A) ${ }^{\mathrm{e}}$} \\
\hline GG, GA & $89(60.5)$ & $20(52.6)$ & $69(63.3)$ & 0.246 \\
\hline \multirow{2}{*}{\multicolumn{5}{|c|}{$A D R B 2 \operatorname{rs} 1042719(\mathrm{G}>\mathrm{C})^{\mathrm{d}}$}} \\
\hline & & & & \\
\hline GG, GC & $125(77.2)$ & $37(82.2)$ & $88(75.2)$ & 0.341 \\
\hline $\mathrm{CC}$ & $37(22.8)$ & $8(17.8)$ & $29(24.8)$ & \\
\hline \multicolumn{5}{|l|}{ ADCY9/ADRB2 } \\
\hline \multicolumn{5}{|l|}{ rs $2531995 / \mathrm{rs} 1042719^{\mathrm{d}}$} \\
\hline $\mathrm{CC} / \mathrm{GG}, \mathrm{GC}$ & $16(9.9)$ & $8(17.8)$ & $8(6.8)$ & 0.073 \\
\hline Others & $146(90.1)$ & $37(82.2)$ & $109(93.2)$ & \\
\hline
\end{tabular}

a 35 missing data for modified Bishop score, ${ }^{\mathrm{b}} 20$ missing data for multiple pregnancy, ${ }^{\mathrm{c}} 2$ missing data for rs879619 and rs2601796, ${ }^{\mathrm{d}} 1$ missing data for rs2230739, ADRB2 rs1042719, and rs2531995/rs1042719, e 16 missing data for PDE4B rs598961. 
Table 5. Multivariable analysis of adverse drug events.

\begin{tabular}{ccc}
\hline Factor & Unadjusted OR (95\% CI) & Adjusted OR (95\% CI) \\
\hline Age $(\geq 30)$ & $1.2(0.6-2.6)$ & \\
Height $(<160 \mathrm{~cm})$ & $2.5(1.1-5.2) *$ & $2.5(1.2-5.2)^{*}$ \\
ADRB2 rs1042719 (GG,GC) & $1.5(0.6-3.6)$ & $2.2(1.1-4.2)^{*}$ \\
ADCY9 rs2531995 (CC) & $2.4(1.2-4.8) *$ & \\
\hline
\end{tabular}

* $p<0.05$. All factors, of which $p$-value was $<0.05$ from univariate analysis in addition to age and ADRB2 rs1042719 were included.

ADCY9 rs879619 and rs2531995 were located in the 3'-UTR region. The results from PolymiRTs showed that ADCY9 rs2531995 ( C > T) created new binding sites for has-miR632, has-miR-4288, and has-miR-346. Context+ score differences were $-0.126,-0.108$, and -0.069 , respectively. ADCY9 rs879619 (C > T) created a new binding site for has-miR-3186-Sp, and its context+ score difference was -0.126 .

\section{Discussion}

This study revealed that $A D C Y 9$ rs879619, gestational age at drug therapy, and modified Bishop score were significant factors for time to delivery after ritodrine administration. ADCY9 rs2531995 and height were significantly associated with ritodrine-induced adverse events.

T allele carriers of $A D C Y 9$ rs879619 showed a significantly longer median time to delivery. Although 3'-UTR regions, in which ADCY9 rs8796195 is located, are a noncoding part of mRNA, they are known to regulate gene expression through degradation, translation, and localization of mRNAs [16]. Therefore, it was speculated that ADCY9 rs879619 could change expression of the ADCY9 gene and its protein. Consistent with our findings, this polymorphism was also found to be associated with percent change in maximum mid-expiratory flow in response to bronchodilators in a previous study investigating the pharmacogenetic effects of $A D C Y 9$ in patients with asthma [9].

Ile772Met, also known as ADCY9 rs2230739, is the most commonly studied SNP of the $A D C Y 9$ gene. In a transfected cell line, Met772-expressing cells had a significantly lower level of $B$-agonist-stimulated ADCY activity $[8,17]$. However, Korean asthmatics carrying Met772 showed a better percent change in forced expiratory volume after 8 weeks' administration of a bronchodilator in a clinical trial [9]. Although patients with CC genotype of ADCY9 rs2230739 had almost half the median time to delivery than that of $\mathrm{T}$ allele carriers, this difference failed to reach statistical significance in our study. This was possibly due to the small sample size.

Ritodrine binds to ADRB2 and activates ADCY to catalyze the formation of cAMP from ATP; however, PDE terminates the signaling of smooth muscle relaxation by degrading cAMP to $5^{\prime}$-AMP [3,7]. Therefore, the ADCY9 gene could interact with the PDE4B and $A D R B 2$ genes in prolonging time to delivery by regulating the intracellular cAMP concentration. After combining genotypes of ADCY9 rs879619, PDE4B rs598961, and ADRB2 rs1042719, AHR for time to delivery increased to 3.2, relative to a value of 2.0 for ADCY9 rs879619 alone.

A previous study evaluating the interaction between $A D C Y 9$ gene polymorphisms and asthma in Brazilian children [10], and another trial using genome-wide association studies in obesity [18], indicated that $A D C Y 9$ rs2531995 was responsible for $A D C Y 9$ expression and intracellular cAMP production. In our study, ADCY9 rs2531995 alone failed to achieve statistical significance in multivariable analysis; however, it showed a significant effect after being combined with PDE4B rs598961 and ADRB2 rs1042719. ADCY9 rs2531995, located in the $3^{\prime}$-UTR region, was also a significant factor in multivariable logistic regression of ritodrine-induced ADEs.

Through our bioinformatics analysis, we found that the variant alleles ( $\mathrm{T}$ alleles) of rs879619 and rs2531995 created new binding sites for miRNA, indicating that both SNPs were potential regulatory elements for post-transcription $A D C Y 9$ gene expression. 
Importantly, miRNA regulates the stability and translation of mRNA by binding to specific regions in the 3'-UTR [19].

Regarding patient characteristics, older gestational age at drug therapy, and higher modified Bishop score were significant risk factors for shorter time to delivery. This can be attributed to the fact that modified Bishop score consists of the degree of cervical dilation and effacement, which are important risk factors for preterm birth [20]. Unexpectedly, lower height was associated with ritodrine-induced ADEs. Further research is required to examine this association.

The limitations of this study are related to its single-center design with a small sample size. With 163 patients, the power to detect a clinically significant decrease of $35 \%$ in time to delivery [21] was calculated to $74 \%$ and $58 \%$ for SNPs with MAF of $20 \%$ and $10 \%$, respectively. Especially for rs2601796, whose observed MAF was around 10\%, it might be more difficult to detect differences than for other SNPs. To afford enough statistical power and validate our hypothesis, further multicenter studies with large sample sizes are needed. The second limitation was a lack of considering the family history of adverse pregnancy outcomes and developmental abnormalities, which could affect preterm labor. However, there is major clinical value in that this is the first study to evaluate a potential role for $A D C Y 9$ in pregnant women with preterm labor. Moreover, the results can be applied to respiratory diseases such as asthma and chronic obstructive pulmonary disease.

This study suggests that $A D C Y 9$ polymorphisms can affect the efficacy and safety of $\beta_{2}$-adrenergic agonists. The results may be appropriate for creating individualized treatment plans in pregnant women with preterm labor.

Author Contributions: J.-Y.P., Y.-J.K., H.-S.H., J.Y. and H.-S.G. participated in research design. N.L. and H.-Y.Y. conducted experiments. N.L. and H.-Y.Y. performed data analysis. J.-Y.P., Y.-J.K. and H.-S.H. drafted a manuscript and J.Y. and H.-S.G. finalized the manuscript. All authors have read and approved the final manuscript.

Funding: This work was supported by the National Research Foundation of Korea (NRF) grant (No. NRF-2010-0022544) funded by the Korea Government (MEST) and the Korea Health Industry Development Institute (KHIDI) (No. HI14C0306) funded by the Ministry of Health and Welfare.

Institutional Review board Statement: The study was conducted according to the guidelines of the Declaration of Helsinki, and approved by the Institutional Review Board (or Ethics Committee) of Ewha Womans University Mokdong Hospital (No. 217-1-26).

Informed Consent Statement: Informed consent was obtained from all subjects involved in the study.

Data Availability Statement: The data that support the findings of this study are available from the corresponding author upon reasonable request.

Conflicts of Interest: The authors declare no conflict of interest.

\section{References}

1. World Health Organization. Preterm Birth: Fact Sheet 2018. Available online: https://www.who.int/news-room/fact-sheets / detail/preterm-birth (accessed on 1 August 2021).

2. Scheid, C.R.; Honeyman, T.W.; Fay, F.S. Mechanism of beta-adrenergic relaxation of smooth muscle. Nature 1979, $277,32-36$. [CrossRef] [PubMed]

3. Sultatos, L.G. Mechanisms of drugs that affect uterine motility. J. Nurse Midwifery 1997, 42, 367-370. [CrossRef] [PubMed]

4. Neilson, J.P.; West, H.M.; Dowswell, T. Betamimetics for inhibiting preterm labour. Cochrane Database Syst. Rev. 2014, 2, CD004352. [CrossRef] [PubMed]

5. $\quad$ Park, J.Y.; Lee, N.R.; Lee, K.E.; Park, S.; Kim, Y.J.; Gwak, H.S. Effects of beta2-adrenergic receptor gene polymorphisms on ritodrine therapy in pregnant women with preterm labor: Prospective follow-up study. Int. J. Mol. Sci. 2014, 15, 12885-12894 [CrossRef] [PubMed]

6. Yee, J.; Hwang, H.S.; Chung, J.E.; Park, J.Y.; Lee, K.E.; Kim, Y.J.; Gwak, H.S. Effects of PDE4 gene polymorphisms on efficacy and adverse drug events of ritodrine therapy in preterm labor patients: A prospective observational study. Eur. J. Clin. Pharmacol. 2019, 75, 1379-1386. [CrossRef] [PubMed]

7. Yuan, W.; López Bernal, A. Cyclic AMP signalling pathways in the regulation of uterine relaxation. BMC Pregnancy Childbirth 2007, 7 (Suppl. 1), S10. [CrossRef] [PubMed] 
8. Small, K.M.; Brown, K.M.; Theiss, C.T.; Seman, C.A.; Weiss, S.T.; Liggett, S.B. An Ile to Met polymorphism in the catalytic domain of adenylyl cyclase type 9 confers reduced beta2-adrenergic receptor stimulation. Pharmacogenetics 2003, 13, 535-541. [CrossRef] [PubMed]

9. Kim, S.H.; Ye, Y.M.; Lee, H.Y.; Sin, H.J.; Park, H.S. Combined pharmacogenetic effect of ADCY9 and ADRB2 gene polymorphisms on the bronchodilator response to inhaled combination therapy. J. Clin. Pharm. Ther. 2011, 36, 399-405. [CrossRef] [PubMed]

10. Teixeira, H.M.; Alcantara-Neves, N.M.; Barreto, M.; Figueiredo, C.A.; Costa, R.S. Adenylyl cyclase type 9 gene polymorphisms are associated with asthma and allergy in Brazilian children. Mol. Immunol. 2017, 82, 137-145. [CrossRef] [PubMed]

11. Kent, W.J.; Sugnet, C.W.; Furey, T.S.; Roskin, K.M.; Pringle, T.H.; Zahler, A.M.; Haussler, D. The human genome browser at UCSC. Genome Res. 2002, 12, 996-1006. [CrossRef] [PubMed]

12. Ward, L.D.; Kellis, M. HaploReg: A resource for exploring chromatin states, conservation, and regulatory motif alterations within sets of genetically linked variants. Nucleic Acids Res. 2012, 40, D930-D934. [CrossRef] [PubMed]

13. Gabriel, S.B.; Schaffner, S.F.; Nguyen, H.; Moore, J.M.; Roy, J.; Blumenstiel, B.; Higgins, J.; DeFelice, M.; Lochner, A.; Faggart, M.; et al. The structure of haplotype blocks in the human genome. Science 2012, 296, 2225-2229. [CrossRef] [PubMed]

14. Bhattacharya, A.; Ziebarth, J.D.; Cui, Y. PolymiRTS Database 3.0: Linking polymorphisms in microRNAs and their target sites with human diseases and biological pathways. Nucleic Acids Res. 2014, 42, D86-D91. [CrossRef] [PubMed]

15. Agarwal, V.; Bell, G.W.; Nam, J.W.; Bartel, D.P. Predicting effective microRNA target sites in mammalian mRNAs. Elife 2015, 4, e05005. [CrossRef] [PubMed]

16. Mayr, C. Regulation by 3'-Untranslated Regions. Annu. Rev. Genet. 2017, 51, 171-194. [CrossRef] [PubMed]

17. Tantisira, K.G.; Small, K.M.; Litonjua, A.A.; Weiss, S.T.; Liggett, S.B. Molecular properties and pharmacogenetics of a polymorphism of adenylyl cyclase type 9 in asthma: Interaction between beta-agonist and corticosteroid pathways. Hum. Mol. Genet. 2005, 14, 1671-1677. [CrossRef] [PubMed]

18. Berndt, S.I.; Gustafsson, S.; Mägi, R.; Ganna, A.; Wheeler, E.; Feitosa, M.F.; Justice, A.E.; Monda, K.L.; Croteau-Chonka, D.C.; Day, F.R.; et al. Genome-wide meta-analysis identifies 11 new loci for anthropometric traits and provides insights into genetic architecture. Nat. Genet. 2013, 45, 501-512. [CrossRef] [PubMed]

19. Bartel, D.P. MicroRNAs: Target recognition and regulatory functions. Cell 2009, 36, 215-233. [CrossRef] [PubMed]

20. Mortensen, O.A.; Franklin, J.; Löfstrand, T.; Svanberg, B. Prediction of preterm birth. Acta Obstet. Gynecol. Scand. 1987, 6, 507-512. [CrossRef] [PubMed]

21. Rozenberg, P.; Rudant, J.; Chevret, S.; Boulogne, A.I.; Ville, Y. Repeat measurement of cervical length after successful tocolysis. Obstet. Gynecol. 2004, 104, 95-99. [CrossRef] [PubMed] 